\title{
Socio-Demographic Predictors of Midwives' Knowledge and Practice Regarding Preconception Care
}

\author{
Niloofar Sattarzadeh ${ }^{1}$, Azizeh Farshbaf-Khalili ${ }^{2}$, Elaheh Khari ${ }^{3}$
}

\begin{abstract}
Objectives: Preconception care focuses on spouses' welfare and gestational health as well as related consequences before and after conception. The present paper was conducted in Tabriz health care centers, Iran in 2015-2016 in order to determine sociodemographic predictors of midwives' practice and knowledge regarding preconception care.

Materials and Methods: This was a cross-sectional study implemented on all midwives (202) occupied in Tabriz health care centers, Iran, using socio-demographic, knowledge and practice questionnaires. The instrument validity was determined based on content validity index (CVI) and CVR methods while its reliability was determined from 2 aspects of repeatability (ICC) and internal consistency (Cronbach alpha coefficient). The socio-demographic and knowledge data questionnaires were completed by midwives while observational checklist of practice was completed by researcher. The data were statistically analyzed using descriptive and inferential methods.

Results: Mean (SD) score of midwives' knowledge was $73.21( \pm 11.83)$ and mean $(\mathrm{SD})$ score of midwives' practice was $80.31( \pm 12.25)$. According to Pearson test, the direct relation between knowledge and practice was not significant $(P=0.133, r=0.238)$. According to multivariate linear regression analysis, age, educational level, employment status and work experience were defined as predictors of midwives' knowledge and age, employment status and job responsibilities as predictors of midwives' practice.

Conclusion: With regard to the direct correlation between knowledge and practice, improvement of midwives' knowledge and so paying attention to the predictors of practice such as employment status and job responsibilities in order to promote midwife's motivation and practice seems to be essential to improve the quality of preconception care.

Keywords: Iran, Knowledge, Midwifery, Preconception care
\end{abstract}

\section{Introduction}

Maternal and infant health is an important indicator of health promotion which determines the health status of community and future generations. The goal of preconception care is to reduce the risk of adverse health effects for the woman, fetus, or neonate by optimizing the woman's health and knowledge before planning and conceiving a pregnancy. Because reproductive capacity spans almost four decades for most women, optimizing women's health before and between pregnancies is an ongoing process that requires access to and the full participation of all segments of the health care system (1).

Preconception care includes a wide range of diagnostic procedures, control and care of chronic and sexually transmitted diseases in women of childbearing age $(2,3)$. According to ACOG (American College of Obstetricians and Gynecologists) statement published in 2005, preconception care includes reducing risk factors associated with pregnancy and promotion of women and babies' health status. It could be applied through higher awareness related to planning and decisions about pregnancy $(1,4)$.

According to the World Health Organization (WHO) report in 2013, almost 289000 women annually die due to complications related to pregnancy and childbirth while most of these deaths occur in developing countries. Many of these complications occur prior to pregnancy period that most of which are preventable and strongly associated with access to health services, poverty, inadequate knowledge, health services and cultural factors $(2,5)$.

In 2013, the maternal mortality ratio was reported to be about 23 of one thousand live births in Iran $(6,7)$. Neonatal and infant mortality rate were respectively 11 and 15 per 1000 live births in Iran in 2012 (8). Public health services introduced preconception care as the essential component of prenatal care. The Center for Disease Control and Prevention (CDC) in 2006 has recommended pre-impregnation care guide to change the habits and behavior of men and women in relation to preimpregnation health $(9,10)$.

The preconception care was considered in Iran subsequent to the formation of Committee for the Prevention of Maternal, Perinatal and Infant Mortality (11). Midwives as individuals responsible for offering preconception care should have adequate information about its benefits. They should assess the women referents in every visit and provide them with adequate trainings on importance of lifestyle and its impact on their current health (12).

Since midwives play important role in providing health 
care and improving the health condition of mothers and children, midwifery is considered as a preventive medicine and so realization of health goals in the area of maternal and child health requires improved quality of pre-pregnancy by midwives $(13,14)$.

Bayrami et al conducted a study to examine the knowledge, attitude and practice of 218 employees of health system to preconception care in Iran and concluded that health workers had average awareness to preconception care and their practice was in average level (15). The limitations of present study include lack of separation of different groups of health care workers and inadequate number of midwives under study. Moreover they did not determine the predictors of knowledge and practice.

The study by van Heesch et al in the Netherlands indicated that midwives mentioned that the accessible preconception care and its effects are important factors to achieve the goals of improving maternal health during pregnancy, however longer time is needed to improve practice and increase knowledge and awareness (16).

Midwives work is based on a comprehensive program in the field of maternal and child care in order to improve health care, so their training should be proportionate to the health programs at the international level $(17,18)$.

According to mentioned studies, midwives are the core of preconception care in health system. The present study was conducted to determine socio-demographic predictors of midwives' practice and knowledge regarding preconception.

\section{Materials and Methods}

This was a cross-sectional descriptive-analytical study. After receiving permission from the Ethics Committee of Tabriz University of Medical Sciences, and also coordination with Research office of Faculty of Nursing and Midwifery as well as Health Vice chancellor, research was implemented on all of the midwives occupied at health care centers (202 midwives) of Tabriz, Iran based on census sampling method with sample size equal to research community centers in 2015-2016.

Inclusion criteria were willingness to participate in the study with more than one year of working experience and exclusion criterion was individual's withdrawal from the study. Study and its objectives were explained to the midwives and then participants signed an informed consent to participate in the study.

Questionnaires were delivered in a quiet environment. The data collection instrument included 1) Sociodemographic characteristic questionnaire on age, educational level, marital status, employment status, years of service, years of graduation, type of university, job responsibilities, number of children, average preconception care per month, attending workshops related to the promotion of maternal health, 2) Researcher-made knowledge and practice questionnaire designed based on a review of the literature and guidelines of integrated maternal health care $(19,20)$. Knowledge questionnaire consisted of 22 multiple-choice questions each with one "correct" answer. The "incorrect" and "I don't know" choices were awarded with zero while "correct" choice scored with point 1 . Attainable score ranged between 0 and 22 that converted to percent.

The content validity was determined based on content validity index (CVI) included relevance, clarity and simplicity of each of the questions while content validity ratio (CVR) included necessity of items. The knowledge CVI as well as CVR were respectively 95\% and $89 \%$. After implementation of pre-test and post-test on 20 people, instrument reliability with interclass correlation coefficient (ICC) with 95\% conference coefficient was 0.98 (0.96-0.99). The Cronbach alpha coefficient was equal to 0.84 .

The practice observational checklist contained 26 3 -option questions. Each of the completely conducted practices was scored with point 2 , incompletely conducted practices with point 1 and practices not conducted with point 0 . Total attainable score ranged between 0 and 52 that were reported based on percent. Midwives' practice measurement was implemented by the researcher. The practice CVI as well as CVR were respectively $1.00 \%$ and $99 \%$. Moreover, 2 observers of practice completed the observational checklist simultaneously for each midwife and totally on 15 people and observers' reliability was examined with ICC method. The Cronbach alpha coefficient was equal to 0.79 .

Data were analyzed based on statistical descriptive methods (central and dispersion parameters) and inferential statistics including Pearson, independent $t$ test, one-way analysis of variance (ANOVA) and multivariate linear test using SPSS 21. To describe the demographic characteristics, knowledge and practice of midwives occupied in health care centers of Tabriz, descriptive statistics method including frequency and percentage, mean and standard deviation were applied. To determine the relationship between knowledge and practice of midwives with demographic characteristics, bivariate independent $t$ test and one-way ANOVA were applied. Independent variables with $P<0.2$ based on bivariate tests were included in multivariate linear regression model. To estimate the effect of independent variables (sociodemographic characteristics) on dependent variable (attitude and practice) and to control the confounding variables multivariate linear regression model with backward strategy was applied. Before multivariate analysis, regression assumptions such as residuals normality, homogeneity of residuals variance, linearity, outlier data and residuals' dependence were examined. To determine the relation between knowledge and practice, Pearson correlation test was applied. The entire analyses were implemented using SPSS 21 software.

\section{Results}

Totally, 202 midwives working in health centers were recruited for this study in 2015 . The mean (standard deviation) age of midwives was 36.74 years $( \pm 7.91)$, work 
experience 11.87 years $( \pm 7.93)$, years of graduation 12.47 years $( \pm 7.95)$, number of care per month $5.02( \pm 3.25)$ and number of children $1.6( \pm 0.77)$. The majority of midwives were married, contractual employee with Bachelor's degree working in private centers, graduated from public university, had multiple work responsibility (Table 1).

The mean (SD) score of knowledge and practice were $73.21( \pm 11.83)$ and $80.33( \pm 12.25)$, respectively. Based on Pearson correlation test, there was a direct relationship

Table 1. Socio-Demographic Characteristics of Midwives $(n=202)$

\begin{tabular}{|c|c|}
\hline Variable & No. (\%) \\
\hline \multicolumn{2}{|l|}{ Age } \\
\hline $23-30$ & $61(30.5)$ \\
\hline $31-40$ & $67(33.5)$ \\
\hline $41-50$ & $65(32.5)$ \\
\hline$>50$ & $7(3.5)$ \\
\hline Mean (SD) & $36.74(7.91)$ \\
\hline \multicolumn{2}{|l|}{ Employment status } \\
\hline Registered & $88(44.0)$ \\
\hline Obligatory & $13(6.5)$ \\
\hline Contractual & $99(49.5)$ \\
\hline \multicolumn{2}{|l|}{ Years of graduation } \\
\hline $1-10$ & $93(46.7)$ \\
\hline $11-20$ & $73(36.7)$ \\
\hline $21-30$ & $33(16.6)$ \\
\hline Mean (SD) & $12.47(7.95)$ \\
\hline \multicolumn{2}{|l|}{ Marital status } \\
\hline Single & $48(24.1)$ \\
\hline Married & $151(75.9)$ \\
\hline \multicolumn{2}{|l|}{ Number of children } \\
\hline $0-1$ & $85(56.3)$ \\
\hline $2-3$ & $66(43.7)$ \\
\hline Mean (SD) & $1.60(0.77)$ \\
\hline \multicolumn{2}{|l|}{ Attending workshop } \\
\hline Yes & $174(87.9)$ \\
\hline No & $24(12.1)$ \\
\hline \multicolumn{2}{|l|}{ Level of education } \\
\hline Associate Degree & $23(11.5)$ \\
\hline Bachelor & $172(86.0)$ \\
\hline Master of Science & $5(2.5)$ \\
\hline \multicolumn{2}{|l|}{ Years of service } \\
\hline $1-10$ & $94(47.0)$ \\
\hline $11-20$ & $77(38.5)$ \\
\hline $21-30$ & $29(14.5)$ \\
\hline Mean (SD) & $11.87(7.93)$ \\
\hline \multicolumn{2}{|l|}{ Kind of university } \\
\hline Private & $81(40.7)$ \\
\hline Public & $118(59.3)$ \\
\hline \multicolumn{2}{|l|}{ Job responsibility } \\
\hline Multiple & $167(84.3)$ \\
\hline Single & $31(15.7)$ \\
\hline \multicolumn{2}{|l|}{ Number of care } \\
\hline $1-5$ & 117 (66.9) \\
\hline $6-11$ & $51(29.1)$ \\
\hline$>11$ & $7(4.0)$ \\
\hline Mean $(S D)^{*}$ & $5.02(3.25)$ \\
\hline \multicolumn{2}{|l|}{ Kind of healthcare } \\
\hline Private & $14(57.0)$ \\
\hline Public & $86(43.0)$ \\
\hline
\end{tabular}

between knowledge and practice, however it was not at significance level $(P=0.133, r=0.238)$ (Table 2$)$.

Maximum knowledge scores were related to the beginning time of folic acid inatake (99\%) and minimum scores were related to clinical assessment of women with overt diabetes before pregnancy (9.9\%). Maximum scores of midwives' practice were in prescribing acid folic (98.8\%) while the minimum scores were related to mental health training $(22.5 \%)$.

According to multivariate linear regression model, age, education level, employment status and years of service by adjusting other variables were predictors of knowledge which could explain $44.1 \%$ of variance in knowledge scores (Table 3).

According to multivariate linear regression model, age, employment status and job responsibilities by adjusting other variables were predictors of practice which could explain $52.6 \%$ of variance in practice scores. So that, midwives with "registered employment" who had "single responsibility" and aged in groups 31-40 had better practice (Table 4).

\section{Discussion}

According to the results of this research, the average knowledge and practice scores of midwives were at a medium to good level. Age, education level, employment status and years of service were predictors of knowledge. Results showed that age, employment status and job responsibilities were predictors of practice.

The present study was consistent with the study by Bayrami et al and Bernstein et al which showed that midwives' knowledge to preconception care was at moderate level. It was inconsistent with the study Bayrami et al that midwives' practice was at weak level $(15,20)$ which may have occurred due to different research environments and the limited number of midwives. However, holding educational workshops and standing educational programs as well as continues monitoring and assessment of the personnel practice according to international standards could be helpful in promotion of the quality of preconception services.

The study by Dattijo et al, is in agreement with current study showing that there were significant relation between knowledge and education level and employment status (21).

The study by Bahri et al showed that there was no significant relation between knowledge and years of service and the reason behind this nonconformity may be attributed to different research populations (22).

The weakest midwives' practice was related to mental health, sexual health and nutrition trainings while the maximum practice was related to folic acid intake, pregnancy history record and calculation of body mass index (2). The study of Sadeghi et al showed that significant relation was observed between employment status and practice (23). However, the study of Esmailpour et al indicated no significant relation between age and 
Table 2. Relationship Between Knowledge and Practice

\begin{tabular}{lccccc}
\hline Variable & Mean (SD) & Attainable Range & Min. & Max. & r \\
\hline Knowledge & $73.21(11.83)$ & $0-100$ & 36 & 100 & 0.133 \\
Practice & $80.31(12.25)$ & $0-100$ & 36 & 100 & \\
\hline
\end{tabular}

Table 3. Socio-Demographic Predictors of Midwives Knowledge

\begin{tabular}{|c|c|c|c|c|c|c|}
\hline Variable & & $\mathrm{n}$ & Mean (SD) & $P^{\mathrm{a}}$ & B (95\% Cl) & $\boldsymbol{P}^{\mathrm{b}}$ \\
\hline & $23-30$ & 61 & $74.49(12.71)$ & & Reference & \\
\hline \multirow[t]{5}{*}{ Age } & $31-40$ & 67 & 74.15(9.97) & 0.019 & $-5.19(-11.85$ to 1.33$)$ & 0.127 \\
\hline & $41-50$ & 67 & $72.44(11.65)$ & & $-5.89(-12.12$ to 0.95$)$ & 0.064 \\
\hline & $>50$ & 5 & $60.19(16.05)$ & & $-19.57(-32.53$ to -6.62$)$ & 0.003 \\
\hline & Mean & & $73.21(11.83)$ & 0.125 & $0.55(0.07$ to 1.03$)$ & 0.025 \\
\hline & Master of science & 5 & $65.02(12.14)$ & & Reference & \\
\hline \multirow[t]{3}{*}{ Level of education } & Associate degree & 23 & $66.45(11.95)$ & & $5.339(-5.76$ to 16.44$)$ & 0.344 \\
\hline & Bachelor of science & 172 & $74.36(11.47)$ & 0.003 & $8.364(3.63$ to 13.09$)$ & 0.001 \\
\hline & Registered & 88 & $70.47(12.14)$ & 0.010 & Reference & \\
\hline \multirow[t]{2}{*}{ Employment status } & Obligatory & 13 & 77.92(8.59) & & $10.33(2.31$ to 18.36$)$ & 0.012 \\
\hline & Contractual & 99 & $75.02(11.46)$ & & $4.95(0.64$ to 9.28$)$ & 0.025 \\
\hline \multirow[t]{5}{*}{ Years of service } & $1-10$ & 94 & $73.57(11.61)$ & & $-2.67(-17.71$ to 12.36$)$ & 0.726 \\
\hline & $11-20$ & 77 & $75.04(11.40)$ & 0.009 & $7.141(1.41$ to 12.87$)$ & 0.015 \\
\hline & $21-30$ & 29 & $67.26(12.14)$ & & Reference & 0.824 \\
\hline & Mean & & $73.21(11.83)$ & 0.054 & $-0.34(-0.86$ to 0.19$)$ & 0.209 \\
\hline & $1-10$ & 93 & $74.16(11.82)$ & & & \\
\hline \multirow[t]{3}{*}{ Years of graduation } & $11-20$ & 73 & $73.85(11.30)$ & 0.151 & & \\
\hline & $21-30$ & 33 & $69.58(12.74)$ & & & \\
\hline & Mean & & $73.21(11.83)$ & 0.077 & & \\
\hline \multirow[t]{2}{*}{ Kind of university } & Private & 81 & $72.61(11.49)$ & 0.576 & & \\
\hline & Public & 118 & $73.57(12.13)$ & & & \\
\hline \multirow[t]{2}{*}{ Marital Status } & Single & 48 & $74.70(11.48)$ & 0.341 & & \\
\hline & Married & 151 & $72.82(11.92)$ & & & \\
\hline \multirow[t]{2}{*}{ Work responsibility } & Multiple & 167 & $73.38(11.78)$ & 0.805 & & \\
\hline & Single & 31 & $72.80(12.43)$ & & & \\
\hline \multirow[t]{2}{*}{ Number of children } & $0-1$ & 85 & $73.54(11.57)$ & 0.408 & & \\
\hline & $2-3$ & 66 & $71.90(12.40)$ & & & \\
\hline \multirow[t]{3}{*}{ Number of care } & $1-5$ & 117 & $72.86(11.90)$ & 0.999 & & \\
\hline & $6-11$ & 51 & $72.91(12.88)$ & & & \\
\hline & $>11$ & 7 & $73.05(10.23)$ & & & \\
\hline \multirow[t]{2}{*}{ Attending workshop } & Yes & 174 & $73.12(11.74)$ & 0.836 & & \\
\hline & No & 24 & $73.66(13.15)$ & & & \\
\hline \multirow[t]{2}{*}{ Kind of healthcare } & Public & 14 & $71.86(13.02)$ & 0.165 & & \\
\hline & Private & 86 & $74.22(10.79)$ & & & \\
\hline
\end{tabular}

Adjusted $\mathrm{R}^{2}=44.1 \%$

a One-way ANOVA, independent samples $t$ test, bivariate Pearson correlation.

${ }^{\mathrm{b}}$ Multivariate linear regression.

employment status with practice; this disagrees with our study which can be attributed to different instruments used for practice and research purposes (24).

Recognition of socio-demographic factors of staffs could be beneficial to increase successful practice and planning of organizations. It could also affect the knowledge, practice and job skills of employees $(22,25)$. The study by Heyes et al indicated that proper training and counseling before pregnancy should be comprehensively implemented in health centers which could be possible due to adequate knowledge and skill of employees (26). According to the study by Shahidi et al in Esfahan, women's awareness of their risk factors before pregnancy lead to improving the pregnancy outcome (27).

According to the study by van Heesch et al, provision of more training to health care workers is recommended to increase their knowledge and pre-pregnancy services (16). Increased knowledge and awareness are essential factors to improve practice.

Based upon the results of this study, midwives in age groups of 31-40 years who were registered and had single responsibility had better practice. It seems that having work experience, stability of employment status and having determined rather than dispersed and 
Table 4. Socio-Demographic Predictors of Midwives Practice

\begin{tabular}{|c|c|c|c|c|c|c|}
\hline Variable & & $\mathbf{n}$ & Mean (SD) & $P^{a}$ & B $(95 \% \mathrm{Cl})$ & $P^{b}$ \\
\hline & $23-30$ & 61 & $76.93(13.70)$ & & Reference & \\
\hline \multirow[t]{5}{*}{ Age } & $31-40$ & 67 & 84.55 (11.65) & $<0.001$ & $3.70(-1.674$ to 9.07$)$ & 0.174 \\
\hline & $41-50$ & 67 & $83.19(7.16)$ & & 0.974 (-8.34 to10.28) & 0.835 \\
\hline & $>50$ & 5 & $60.79(8.16)$ & & $-19.93(-32.59$ to-7.28) & 0.002 \\
\hline & Mean & & $80.31(12.25)$ & 0.977 & & \\
\hline & Associate degree & 23 & 77.71 (12.98) & & & \\
\hline \multirow[t]{3}{*}{ Level of education } & Bachelor of Science & 17 & 80.55 (12.24) & 0.614 & & \\
\hline & Master of Science & 5 & $89.13(12.25)$ & & & \\
\hline & Registered & 88 & $83.26(12.24)$ & & Reference & \\
\hline \multirow[t]{2}{*}{ Employment status } & Obligatory & 13 & $81.28(6.55)$ & 0.106 & $-0.33(-12.34$ to11.67) & 0.956 \\
\hline & Contractual & 99 & $77.23(12.68)$ & & $-8.59(-13.47$ to -3.72$)$ & 0.001 \\
\hline \multirow[t]{5}{*}{ Years of service } & $1-10$ & 94 & $78.52(12.63)$ & & & \\
\hline & $11-20$ & 77 & $84.00(10.00)$ & 0.176 & & \\
\hline & $21-30$ & 29 & 78.69 (14.28) & & & \\
\hline & Mean & & $80.31(12.25)$ & 0.413 & & \\
\hline & $1-10$ & 93 & $78.62(12.51)$ & & & \\
\hline \multirow[t]{3}{*}{ Years of Graduation } & $11-20$ & 73 & $84.43(10.21)$ & 0.019 & & \\
\hline & $21-30$ & 33 & $80.61(11.51)$ & & & \\
\hline & Mean & & $80.31(12.25)$ & 0.678 & & \\
\hline \multirow[t]{2}{*}{ Kind of university } & Private & 81 & $78.81(13.01)$ & 0.268 & & \\
\hline & Public & 118 & $81.86(11.37)$ & & & \\
\hline \multirow[t]{2}{*}{ Marital Status } & Single & 48 & $77.55(12.71)$ & 0.455 & & \\
\hline & Married & 151 & $81.27(12.04)$ & & & \\
\hline \multirow[t]{2}{*}{ Work responsibility } & Single & 31 & 75.29 (14.99) & & Reference & \\
\hline & Multiple & 167 & $81.46(11.45)$ & 0.080 & $-7.26(-13.36$ to -1.15$)$ & 0.020 \\
\hline \multirow[t]{2}{*}{ Number of children } & $0-1$ & 85 & $81.19(11.35)$ & 0.952 & & \\
\hline & $2-3$ & 66 & $81.38(13.19)$ & & & \\
\hline \multirow[t]{3}{*}{ Number of care } & $1-5$ & 117 & $81.01(11.83)$ & 0.431 & & \\
\hline & $6-11$ & 51 & $79.23(8.61)$ & & & \\
\hline & $>11$ & 7 & 91.30 & & & \\
\hline \multirow[t]{2}{*}{ Attending workshop } & Yes & 174 & $80.50(12.71)$ & 0.658 & & \\
\hline & no & 24 & $78.39(9.81)$ & & & \\
\hline \multirow[t]{2}{*}{ Kind of healthcare } & public & 14 & $80.97(10.45)$ & 0.673 & & \\
\hline & Private & 86 & $79.80(13.55)$ & & & \\
\hline
\end{tabular}

Adjusted $\mathrm{R}^{2}=52.6 \%$

a One-way ANOVA, independent samples $t$ test, bivariate Pearson correlation.

${ }^{b}$ Multivariate linear regression.

unspecialized duties can be effective factors in promotion of preconception services quality.

The results of present paper will be beneficial to improve employment conditions, identify motivational factors and attend economic difficulties affecting the practice. To achieve WHO goals in term of improving maternal health and reducing child mortality, improved practice of an organization is necessary which depends on high knowledge and practice of entire staffs. This knowledge could be profitable to successful information, practice and planning in order to improve the maternal and child health.

The limitations of present study included disinclination to participate in the study and to fill out the questionnaires. This difficulty was removed somewhat by presenting anonym questionnaires and placing the completed questionnaires in the closed boxes. The other limitation was inadequate referrals of health care seekers to implement preconception care which were obviated by time schedule and waiting further referrals. The present study included only the population in urban areas which could not be generated to rural areas. Moreover, this study was a quantitative research that researchers suggest to do further studies with qualitative method.

\section{Conclusion}

Based on the results, knowledge and practice level of midwives was at moderate to good level. With regard to the direct correlation between knowledge and practice, improvement of midwives' knowledge and so paying attention to the predictors of practice such as employment status and job responsibilities in order to promote midwife's motivation and practice seems to be essential to improve the quality of preconception care.

\section{Ethical Issues}

This study was conducted on midwives after receiving permission from the Ethics Committee of Deputy of 
Research and Technology at Tabriz University of Medical Sciences (No. 1394428).

\section{Conflict of Interests}

The authors declare no conflict of interests.

\section{Financial Support}

This study was supported financially by the Office of the Vice Chancellor for Research of Tabriz University of Medical Sciences.

\section{Acknowledgments}

Hereby, we would like to thank the Deputy Research of Tabriz University and Faculty of Nursing and Midwifery, Tabriz University of Medical Sciences and all the midwives who patiently assisted us in data collecting.

\section{References}

1. American College of Obstetricians and Gynecologists. ACOG Committee Opinion number 313, September 2005. The importance of preconception care in the continuum of women's health care. Obstet Gynecol 2005;106(3):665-6.

2. World Health Organization. Maternal mortality 2013. http://www.who.int/mediacentre/factsheets/fs348/en/. Updated May 2014.

3. Broussard DL, Sappenfield WB, Fussman C, Kroelinger CD, Grigorescu V. Core state preconception health indicators: a voluntary, multi-state selection process. Matern Child Health J. 2011;15(2):158-68. doi: 10.1007/s10995-0100575-x.

4. Johnson K, Posner SF, Biermann J, et al. Recommendations to improve preconception health and health care--United States. A report of the CDC/ATSDR Preconception Care Work Group and the Select Panel on Preconception Care. MMWR Recomm Rep. 2006;55(RR-6):1-23.

5. World Health Organization. Preconception care to reduce maternal and childhood 2012. http://www.who.int/ iris/bitstream/10665/78067/1/9789241505000_eng.pdf. Updated 2015.

6. World Health Organization. Maternal mortality country profiles 2013. http://www.who.int/gho/maternal_health/ countries/en/. Updated June 2015.

7. World Health Organization. Children: reducing mortality. http://www.who.int/mediacentre/factsheets/fs 178/en/. Updated September 2014.

8. United Nations Children's Fund. Statistic of child death 2012. http://www.unicef.org/infobycountry/iran_statistics. html. Updated December 27, 2013

9. Biermann J, Dunlop AL, Brady C, Dubin C, Brann A Jr. Promising practices in preconception care for women at risk for poor health and pregnancy outcomes. Matern Child Health J. 2006;10(5 Suppl):S21-8.

10. Downs DS, Feinberg M, Hillemeier MM, et al. Design of the Central Pennsylvania Women's Health Study (CePAWHS) strong healthy women intervention: improving preconceptional health. Matern Child Health J. 2009;13(1):18-28. doi: 10.1007/s10995-008-0323-7.
11. Hatami H, Razavi M, Ardebili EH, Majlesi F. Public Health. Tehran: Arjmand Publication; 2010. [Persian].

12. Lassi ZS, Imam AM, Dean SV, Bhutta ZA. Preconception care: caffeine, smoking, alcohol, drugs and other environmental chemical/radiation exposure. Reprod Health. 2014;11 Suppl 3:S6.

13. Korenbrot CC, Steinberg A, Bender C, Newberry S. Preconception care: a systematic review. Matern Child Health J. 2002;6(2):75-88.

14. International Definition of the Midwife 2014. http:// www.internationalmidwives.org/who-we-are/policy-andpractice/icm-international-definition-of-the-midwife/. Updated 2015.

15. Bayrami R, Ebrahimipour H, Ebrahimi M, Forootani M, Najafzadeh B. Health care provider s' knowledge, attitude and practice regarding pre-conception care. J Res Health. 2013;3(4):519-26

16. van Heesch PN, de Weerd S, Kotey S, Steegers EA. Dutch community midwives' views on preconception care. Midwifery. 2006;22(2):120-4. doi: 10.1016/j. midw.2005.06.003.

17. DeSandre CA. Midwives as primary care providers. J Midwifery Womens Health. 2000;45(1):81-3.

18. Cuningham G, Leveno JK, Bloom LS, Hauth CJ, Rouse JD, Spong YC. Williams Obstetrics. 23rd ed. New York: McGraw Hill Professional; 2010.

19. Science MoHaM. Integrated Maternal Health Care. 4th ed. Tehran: Negah; 2013. [Persian].

20. Bernstein PS, Sanghvi T, Merkatz IR. Improving preconception care. J Reprod Med. 2000;45(7):546-52.

21. Dattijo L, Andreadi N, Aminu B, Umar N, Black K. Knowledge of infertility among infertile women in Bauchi, Northern Nigeria. Int J Womens Health Reprod Sci. 2016;4(3):103-9. doi: 10.15296/ijwhr.2016.25.

22. Bahri N, Iliati HR, Bahri N, Sajjadi M, Boloochi T. Effects of oral and dental health education program on knowledge, attitude and short-time practice of pregnant women (Mashhad-Iran). J Mashhad Dent Sch 2012;36(1):1-2. [Persian].

23. Sadeghi A, Darzi RS, Toroski M, Emami O, Heydari G, Shahraki H. Viewpoints of the staff of North Khorasan University of Medical Sciences about the motivational and hygiene factors affecting their performance and satisfaction. Sadra Med Sci J. 2014;4(2):111-22. [Persian].

24. Esmailpour N, Mirblouk F, Shodjaei Tehrani H, Poorseyad Reza A, Dalil Heirati SF. Survey the knowledge, attitude and practice on popsmear in nurses and midwives. J Guilan Univ Med Sci. 2011;20(77):81-8. [Persian].

25. Khuwaja AK, Qureshi R, Andrades M, Fatmi Z, Khuwaja NK. Comparison of job satisfaction and stress among male and female doctors in teaching hospitals of Karachi. J Ayub Med Coll Abbottabad. 2004;16(1):23-7.

26. Heyes T, Long S, Mathers N. Preconception care: practice and beliefs of primary care workers. Fam Pract. 2004;21(1):22-7.

27. Shahidi S, Aghdak P, Izadi M. Effect of pre-conception care protocol on women's awareness. Iran J Med Educ. 2011;10(5):525-32. [Persian].

Copyright (C) 2017 The Author (s); This is an open-access article distributed under the terms of the Creative Commons Attribution License (http://creativecommons.org/licenses/by/4.0), which permits unrestricted use, distribution, and reproduction in any medium, provided the original work is properly cited. 